\title{
CONSIDERAÇÕES SOBRE CORPO E LINGUAGEM NA CLÍNICA E NA TEORIA LACANIANA
}

\author{
Michele Cukiert ${ }^{1}$ \\ Instituto de Psicologia-USP
}

$O$ artigo focaliza as relações entre corpo e linguagem (e sua transformação) ao longo do ensino de Lacan. Discute críticas dirigidas às formulações lacanianas no sentido de que, com a ênfase sobre a linguagem, Lacan teria amputado do sujeito em Psicanálise sua realidade sensivel. Mostra que Lacan, postulando o inconsciente estruturado como linguagem, não exclui a corporeidade de seu esquema mental nem reduz o fenômeno analítico ao simbólico (discurso).

Descritores: Psicanálise. Teoria lacaniana. Corpo. Lacan, Jacques, 1901-1981.

\section{O Corpo na Tópica Lacaniana}

Oomo se sabe, o conjunto terminológico Imáginário, Simbólico e Real (a chamada tópica lacaniana) está na base de todo o ensino de Lacan. Ao longo de sua teorização, entretanto, os registros vão sendo articulados e pensados por meio de novas perspectivas e precisões. Em termos gerais, consideramos que Lacan desenvolve o Registro Imaginário, em seguida, o Simbólico e, posteriormente, a ênfase será dada ao Real.

Segundo Roudinesco e Plon (1998), a tópica se transforma ao longo do ensino de Lacan, tendo passado por duas organizações sucessivas: "na primeira (1953-1970), o simbólico exerceu a primazia sobre as outras duas

1 Mestre e Doutoranda do programa de pós-graduação em Psicologia Clínica do Instituto de Psicologia - USP. Endereço eletrônico: michele@ usp.br. 
instâncias (S.R.I.) e, na segunda (1970-1978), o real é que foi colocado na posição dominante (R.S.I.)” (p. 755).

Cesarotto e Leite (1993) consideram que os registros lacanianos são "descritos por ele [Lacan] como as três dimensões do espaço habitado pelos seres falantes, como é revelado pela experiência analítica" (p. 73). Os autores indicam que a sequiência do ensino lacaniano pode ter como modelo, ao invés de uma referência temporal, a "lógica interna dos desenvolvimentos teóricos, [que] apontaria [entretanto] três etapas" (p. 112). A primeira, de 1936 a 1953, delimitaria o registro do Imaginário. A segunda, de 1953 a 1976, evidenciaria o registro do Simbólico. A terceira, de 1976 a 1980, enfatizaria o registro do Real e a "interrelação destes três registros (...)" (p. 112).

Vale lembrar que, por mais que Lacan articule gradativamente os três registros em sua teoria, passando a concebê-los no quadro de uma tópica, o conceito de Imaginário, Simbólico e Real são inseparáveis e devem ser pensados formando uma estrutura.

Nesse contexto, à luz da teoria dos três registros fundamentais ${ }^{2}$, o corpo na teoria lacaniana pode ser estudado através de três pontos de vista complementares: do ponto de vista do Imaginário, o corpo como imagem, do ponto de vista do Simbólico, o corpo marcado pelo significante e do ponto de vista do Real, o corpo articulado ao gozo.

Pensar o corpo do ponto de vista do Imaginário nos remete aos primeiros momentos da teoria lacaniana e à forma como a imagem do corpo próprio, a partir do outro, marca a constituição subjetiva e a imagem assumida pelo sujeito.

O corpo, do ponto de vista do Simbólico, implica verificar como se estabelece a relação entre fala-linguagem-corpo. Tendo como referência o texto "Função e Campo da Fala e da Linguagem em Psicanálise", publicado por Lacan em 1953, e sua concepção do primado da linguagem, é preciso levar em conta o corpo marcado pelo Simbólico, suporte do significante, no

2 Questão amplamente discutida em Cukiert (2000). 
qual as diversas partes podem servir de significantes, isto é, ir além de sua função no corpo vivo.

Do ponto de vista do Real, a introdução do conceito de gozo, distinto da noção de prazer, possibilitará definir as diferentes relações com a satisfação que um sujeito falante pode experimentar no uso de um objeto desejado, postulando que a questão da satisfação também se inscreve na rede de sistemas simbólicos que dependem da linguagem.

Além disso, conforme discutirei a seguir, por meio da introdução do registro do Real, Lacan faz uma série de retificações que possibilitam, inclusive, repensar os limites da fala e o lugar do corpo em sua construção teórica.

\section{O Real e o Corpo}

A noção de gozo não é muito presente ao longo da obra freudiana, aparecendo, em geral, como referida ao prazer (gozo da sucção, gozo do amor etc.). Mesmo assim, mais ao final de sua obra, Freud se refere ao gozo não apenas como sinônimo de prazer, mas, segundo Roudinesco e Plon (1998), "articulado com a idéia de repetição, tal como esta seria empregada mais tarde em Mais além do princípio de prazer, por ocasião da elaboração do conceito de pulsão de morte" (p. 299).

Lembremos que, para Freud, o campo do sexual se amplia, passando a manifestar-se e identificar-se em tudo aquilo que diz respeito ao humano (até mesmo na produção artística ou intelectual). Nesse sentido, a noção freudiana de sexualidade fica claramente diferenciada da idéia de genitalidade puramente biológica, conforme adotada, por exemplo, pela Sexologia. Mesmo assim, na origem, com a idéia de apoio, afirma-se em Freud o surgimento do sexual como ancorado, em um primeiro momento, nas funções corporais necessárias à conservação da vida.

Por meio do exemplo do prazer experimentado na atividade oral do lactente, Laplanche e Pontalis (1983) ilustram a maneira como a função corporal fornece à sexualidade a sua fonte ou zona erógena: "indica-lhe imedia- 
tamente um objeto, o seio; finalmente causa um prazer que não é redutível à pura e simples satisfação da fome, uma espécie de brinde de prazer" (p. 66).

Nesse contexto, como indicam Roudinesco e Plon (1998), a idéia de gozo pode ser ligada ao processo do apoio, que leva ao surgimento da pulsão sexual. No momento em que a criança, satisfeita a sua necessidade orgânica, já não se entrega tanto à sucção, mas ao chuchar, observa-se "o nascimento dessa atividade repetitiva, da ordem do gozo, que assinala a entrada na fase de auto-erotismo" (p. 299).

Lacan parte desses elementos para elaborar a noção de gozo, que, em sua obra, será pensada como um dos componentes estruturais do funcionamento psíquico.

Em seguida, tendo em vista a problemática da satisfação e da relação com o outro, Lacan fará a distinção entre o prazer e o gozo. Roudinesco e Plon (1998) esclarecem que

Lacan estabelece uma distinção essencial entre o prazer e o gozo, residindo este na tentativa permanente de ultrapassar os limites do princípio de prazer. Esse movimento, ligado à busca da coisa perdida que falta no lugar do Outro, é causa de sofrimento; mas tal sofrimento nunca erradica por completo a busca do gozo. (p. 300)

O gozo é repensado por Lacan quando da elaboração da teoria do processo da sexuação e do conjunto de fórmulas lógicas que a expressam. Conforme indicam Roudinesco e Plon (1998, p. 300), para Lacan o gozo absoluto não é atingível, pois todo o humano está submetido à castração. Define-se então um gozo fálico para o homem, "limitado, submetido à ameaça da castração, (...) que constitui a identidade sexual do homem", e o gozo feminino que "é diferente e, acima de tudo, sem limite. É pois um gozo suplementar (...), enunciado como tal no (...) seminário Mais ainda".

Nasio (1993) retoma o estatuto do corpo na teoria lacaniana e afirma que ela define o corpo segundo dois parâmetros fundamentais que delimitam o campo psicanalítico: "a fala e o sexo" (p. 148). Essa precisão possibilita estabelecer a distinção entre o corpo da Medicina e o corpo, sexual e gozoso, abordado pela Psicanálise, pois 
contrariamente ao cirurgião, que se coloca diante do corpo de seu doente e o trata como um organismo, sem se preocupar em saber se ele fala ou goza, o psicanalista, por sua vez, deverá constantemente referir-se, direta ou indiretamente, aos parâmetros que são a fala e o sexo, e assim, conceber dois estatutos do corpo: o corpo falante e o corpo sexual. (p. 148)

O corpo falante, conforme assinalado anteriormente, é o corpo marcado pelo Simbólico, tomado como um conjunto de elementos significantes. Ao mesmo tempo, o corpo é sexual, porque "o corpo é todo gozo e porque o gozo é sexual”. Nesse sentido, Nasio (1993, pp. 151-152) propõe que “do ponto de vista do Real, temos o corpo sinônimo de gozo".

As relações entre o corpo e o gozo são repletas de nuanças. Nasio discute o caráter contraditório de que se reveste a definição de gozo na teoria lacaniana (introduzida, segundo ele, por volta de 1967). Lacan repetiu inúmeras vezes que "só existe gozo do corpo". Quase na mesma época, ele afirmou, ao contrário, "a disjunção entre o corpo e o gozo". Na leitura de Nasio, "esses ditos lacanianos não são contraditórios, desde que admitamos que a palavra corpo é empregada com uma acepção diferente em cada uma dessas formulações" (p. 151).

Na primeira, pode-se interpretar que, "para que um corpo goze, (...) é preciso que esteja vivo" (p. 152). Na segunda formulação, na qual se afirma a disjunção entre corpo e gozo, a palavra corpo se traduz por organismo. Assim, "o gozo é (...) radicalmente disjunto do corpo, (...) desde que consideremos esse corpo como o corpo orgânico, aquele de que a psicanálise não tem de se ocupar" (p. 152).

No Seminário O Avesso da Psicanálise, Lacan (1969-1970/1992) considera que o olhar que a análise trouxe acerca do gozo é revolucionário. Com seu tom irônico, ele aponta exatamente essa disjunção entre o gozo e os "processos naturais", afirmando que só há gozo no humano, pois,

o importante é que, natural ou não, é efetiv amente como ligado à própria origem da entrada em ação do significante que se pode falar de gozo. Com que goza a ostra ou o castor, ninguém jamais saberá nada disso porque, faltando significante, não há distância entre o gozo e o corpo. (p. 168) 


\section{Michele Cukiert}

Portanto:

O gozo é exatamente correlativo à forma primeira da entrada em ação do que chamo a marca, o traço unário, que é marca para a morte, se quiserem dar-lhe seu sentido. Observem bem que nada toma sentido até que a morte entre na jogada. (p. 169)

Ou seja, "é a partir da clivagem, da separação entre o gozo e o corpo doravante mortificado, a partir do momento em que há jogo de inscrições, marca do traço unário, que a questão se coloca” (p. 169).

Isso quer dizer que a noção de gozo está plenamente ancorada na corporeidade, referida ao corpo vivo, sem o qual não poderia existir. Paradoxalmente, ela não tem nada de natural, é anti-natural por excelência, pois há uma separação entre corpo (organismo) e gozo, já que no humano, atravessado e constituído pela linguagem, não há mais nada de natural.

Segundo Roudinesco e Plon (1998, p. 645), o registro do Real, introduzido por Lacan em 1953, foi extraído "simultaneamente, do vocabulário da filosofia e do conceito freudiano de realidade psíquica, para designar uma realidade fenomênica que é imanente à representação e impossível de simbolizar". Os referidos autores mostram que Lacan combina "a ciência do real, a heterologia e a noção de realidade psíquica" para construir sua categoria do real, que posteriormente é estabelecido como "um dos três componentes de sua tópica e de sua concepção estrutural de um inconsciente determinado pela linguagem". A introdução desta noção é feita numa conferência intitulada O Simbólico, o Imaginário e o Real. Depois disso, "Lacan adquiriu o hábito de escrever as três palavras com maiúsculas".

Os autores sintetizam o lugar de cada um dos registros lacanianos, no contexto de sua retomada estrutural da obra freudiana, observando que

na categoria do simbólico [Lacan] alinhou toda a reformulação buscada no sistema saussuriano e levi-straussiano; na categoria do imaginário situou todos os fenômenos ligados à construção do eu: antecipação, captação e ilusão; e no real, por fim, colocou a realidade psíquica, isto é, o desejo inconsciente e as fantasias que lhe estão ligadas, bem como um "resto": uma realidade desejante, inacessível a qualquer pensamento subjetivo. (p. 645) 
O Real pode ser pensado como um tempo anterior às palavras, um momento pré-simbólico. De fato, Lacan (1954-1955/1998) se refere a um certo "para além da referência inter-humana, que é, propriamente, o para além simbólico" (p. 101).

Lacan (1960/1998) também aponta o "sentido mortífero" do significante. Ele afirma que "o significante como tal, barrando por intenção primeira o sujeito, nele faz penetrar o sentido da morte. (A letra mata, mas só ficamos sabendo disso pela própria letra.)" (p. 862).

Fink (1998) mostra, de forma bastante didática, no que consiste o Real na teoria lacaniana. Ele retoma a afirmação de Lacan de que "a letra mata (...) o real que havia antes da letra, antes das palavras, antes da linguagem" (p. 43), e articula o Real ao corpo:

O real é, por exemplo, o corpo de uma criança "antes" do domínio da ordem simbólica, antes de controlar os esfíncteres e aprender os costumes do mundo. No curso da socialização, o corpo é progressivamente escrito ou sobrescrito com significantes; o prazer está localizado em determinadas zonas, enquanto outras são neutralizadas pela palavra e persuadidas a se conformarem com as normas sociais e comportamentais. Levando a idéia de Freud sobre a perversidade polimorfa às últimas conseqüências, é possível ver o corpo de uma criança como apenas uma zona erógena contínua, no qual não haveria zonas privilegiadas, nenhuma área na qual o prazer estivesse circunscrito de início. (p .43)

Mas o Real não deve ser entendido apenas como anterior à letra. Fink (1998) observa que o Real não desaparece por completo quando uma criança assimila a linguagem, esclarecendo que esse registro é melhor compreendido como

aquilo que ainda não foi simbolizado, resta ser simbolizado, ou até resiste à simb olização; pode perfeitamente existir "lado a lado" e a despeito da considerável habilidade lingüística de um falante. Nesse sentido, parte do processo psicanalítico envolve claramente permitir a um analisando colocar em palavras aquilo que permanece não simbolizado para ele, verbalizar as experiências que podem ter ocorrido antes do analisando ter sido capaz de pensar sobre elas, falar delas, ou formulá-las de qualquer maneira que seja. (p. 44) 
Como lembra Chemama (1995), o Real, definido como o impossível, "é aquilo que não pode ser simbolizado totalmente na palavra ou na escrita e, por conseqüência, não cessa de não se escrever” (p. 182).

Com a introdução do Real e do gozo, há uma conversão de perspectiva no ensino de Lacan. O Real como substantivo, o impossível de simbolizar, provoca remanejamentos nas concepções lacanianas. Assim, o corpo, além de ser afetado pela linguagem, goza. Miller (1998) retoma as afirmações lacanianas de que "é preciso que haja um corpo para gozar, somente um corpo pode gozar" (p. 93), lembrando que a conseqüência dessa evidência é que o corpo não deve ser pensado só como simbolizado, "significantizado e (...) simbolizado quer dizer mortificado" (p. 95). Para gozar, é necessário o corpo vivo.

Ao mesmo tempo, Lacan (1975/1982) afirma que "o significante é a causa do gozo" (p. 66). Tendo essa proposição em vista, Miller (1998) esclarece que na teoria lacaniana existem dois efeitos do significante no corpo: "um, que é a mortificação, e o outro, que é a produção do mais-de-gozar. Se o significante mata o gozo, da mesma forma o produz" (p. 99). Propõe, ainda, que o essencial "não é que o significante tenha um efeito de mortificação sobre o gozo, é que o significante é causa de gozo, é que o significante tem uma incidência de gozo sobre o corpo. É isso que Lacan chama de sintoma" (p. 99). Assim, o sintoma "inscreve uma relação muito mais direta entre o significante e o gozo" (p. 100), sendo a própria intersecção entre significante e gozo, entre corpo e linguagem.

Robertie (1992, p. 264) também aponta essa mudança de perspectiva no ensino lacaniano. Ele assinala que, a partir de 1964, para Lacan "a fala, unicamente, não constitui fundamento". Assim, nesse período da produção lacaniana surgem várias reformulações e afirmações novas, e "todo o esforço de Lacan consiste em mostrar os limites da fala". 


\section{Corpo e Linguagem: Discussão}

A discussão acerca do lugar do corpo e da linguagem no tratamento analítico e na teoria lacaniana merece uma discussão atenta. Vários autores criticam as formulações lacanianas, afirmando que, com a ênfase sobre a linguagem, ele teria amputado do sujeito em Psicanálise sua realidade sensível. Nesse sentido, apontam os impasses e os riscos que se apresentam ao campo psicanalítico quando se considera, equivocadamente, que pensar o sujeito constituído e atravessado pela linguagem implica em separá-lo do próprio corpo, transformando-o em um sujeito platônico, pura idéia ou representação.

Nos termos dessa leitura, haveria na abordagem lacaniana a prevalência de um formalismo lógico, que teria apagado do sujeito forjado pela Psicanálise suas particularidades diferenciais, quais sejam, o inconsciente e a lógica das pulsões.

Birman (1998), por exemplo, considera que Lacan "procurou articular Hegel e Heidegger, delineando o lugar axial do Outro", mas esqueceu-se de que "a novidade maior de Freud foi a de ter concebido a figura de um sujeito encarnado". Além disso,

a subjetividade foi concebida através da utilização de modelos lógicos e matemáticos. Um sujeito logificado foi a resultante desta empreitada teórica. Assim, seja pela lógica simbólica, seja pela topologia e a lingúística, o efeito foi sempre o mesmo, isto é, a produção de um sujeito distante dos avatares da corporeidade. (p. 169)

Em sua leitura, Birman (1998, p. 170) interpreta que a recorrência dos analistas a uma "perspectiva logificante", fornece ao sujeito uma "ilusão de certeza que apazigua suas dúvidas". Em contrapartida, "as dimensões da finitude e do desamparo do sujeito permanecem evidentemente silenciadas", já que esses registros remetem exatamente à mortalidade e à corporeidade do sujeito. Assim, "a corporeidade do sujeito revela o que é mais incerto na experiência da existência, já que mediante aquela a subjetividade indica a sua falibilidade". 
Nesse contexto, esse autor acredita que, ao excluir o corpo de seu campo de ação e interesse, voltando-se fervorosamente para os registros do pensamento e da linguagem, a Psicanálise corre o risco de ser substituída por outros discursos e práticas terapêuticas atuais que se propõem a intervir sobre o corpo (terapias corporais, terapêuticas farmacológicas etc.).

Lembrando que o corpo é regulado pelos "destinos das pulsões e do desejo", Birman (1998) afirma que "se a psicanálise esquece que o sujeito é encorpado, restringindo-se às leituras do pensamento e da linguagem, (...) no fundamental, a descoberta freudiana foi silenciada" (p. 172). Considera ainda que Freud, com a criação do conceito de pulsão e com a formulação da existência de um sujeito encorpado, indica um caminho para superar o dualismo cartesiano:

o que Freud buscou foi a superação dos registros do pensamento (linguagem) e do corpo pela mediação de uma teoria dos afetos. Desta forma, o sujeito seria corpo e pensamento, marcado então pelos destinos das pulsões. Portanto se inscreveria imediatamente no registro da ação, sem que essa se contrapusesse ao da reflexão. (p. 174)

Por isso tudo, para Birman (1998, p. 175), os analistas devem atentar para o fato de que os analisandos não apenas "têm um corpo", mas também, que "a existência é praxis". Para o autor, o malestar que inquieta os analistas face ao futuro e à dissonância da Psicanálise na pós-modernidade se devem, justamente, ao esquecimento desses aspectos constituintes do sujeito e de sua existência.

Nesse mesmo sentido, Katz (1992) retoma Freud e se refere à noção de corpo erógeno como articuladora das conexões entre psíquico e orgânico. Tendo em vista o conceito de pulsão, as formulações presentes nos Três ensaios sobre a sexualidade, esse autor afirma que Freud, apesar de afastarse do corpo da Fisiologia, postula um estatuto do corpo que "não se reduz unicamente à sua existência enquanto ente assujeitado à dominação simbólica" (p. 21). Segundo Katz, "Freud mostra, de modo extremado, que o corpo erógeno só se faz apoiado ou articulado com o corpo vivo” (p. 23). 
Ainda que, em certo momento, por exemplo, no caso Dora, escrito em 1901, Freud "experimenta reduzir a transferência a um acontecimento pertinentemente simbólico (...), onde deixará de lado, temporariamente, o que se denomina de capacidade do corpo vivo", para Katz (1992, p. 22), ele [Freud] sempre insistirá na articulação de duas vertentes, a "teoria do simbólico" e a "capacidade do corpo vivo".

Entretanto, Katz critica os "desdobramentos da teoria freudiana" que ignoram essa articulação. Mais exatamente, considera que certas leituras afirmam que Freud, "abandonando o corpo dos anatomopatologistas, só se dirigiu à fundamentação de um corpo simbólico, vívido e vivido apenas desde uma cadeia de significações" (p. 23). Aponta ainda que

tal parcialização da Psicanálise leva por vezes a uma leitura metafísica abstrainte de Freud, que afirma que sua teorização última se fundamentaria unicamente em um complexo de Édipo, no qual os sujeitos existiriam porque, à moda de Platão, participariam dele. Afirma-se uma cadeia significante com uma lógica única e unitária, como uma idéia pura exterior aos que lhe são assujeitados, e que seria o que permitiria a fundação do humano, ou do sujeito humano. Sujeito este que, sendo um Nada, nasceria unicamente destinado a introjetar o Outro, e só a isto. E, mais ainda, tal Simbólico Celestial (encomendado pelo Outro do Espírito Santo) seria tão poderoso que faria viver qualquer coisa que ali se inscrevesse (até um elefante, que não teria sua "elefantice" imanente...). Mas isto não é freudiano, por mais psicanalítico que seja para alguns. (pp. 23-24)

Nota-se que essas críticas, lançadas mais ou nenos diretamente ao campo lacaniano, não são fortuitas. De fato, se a perspectiva da linguagem renova a pesquisa com o inconsciente, ela não deixa de estar sujeita a abusos e mal-entendidos.

Essa crítica não foi estranha à Lacan (1964/1988) que, em resposta aos que afirmam que "a psicanálise é, à primeira vista, propícia a nos dirigir por um idealismo", afirma:

Deus sabe que se lhe tem reprochado isto - ela reduz a experiência, dizem alguns, que nos solicita a achar nos duros choques do conflito, da luta, mesmo da exploração do homem pelo homem, as razões de nossa deficiência - ela conduz a uma ontologia das tendências, que tem por primitivas, internas, já dadas pela condição do sujeito. 


\title{
Michele Cukiert
}

\begin{abstract}
Basta nos reportarmos ao traçado dessa experiência depois de seus primeiros passos, para vermos, ao contrário, que ela não nos permite de modo algum nos resolvermos por um aforismo como a vida é um sonho. Nenhuma praxis, mais do que a análise, é orientada para aquilo que, no coração da experiência, é o núcleo do real. (p. 55)
\end{abstract}

Com a ênfase sobre a linguagem, Lacan não pretendeu excluir o corpo de seu esquema mental. Porém, é impossível negar que em certo momento de sua elaboração teórica, ele de fato tenha priorizado o registro Simbólico. Miller (1998) identifica que há, realmente, um primeiro momento na elaboração lacaniana, no qual, com a ênfase sobre o simbólico, ele teria deixado o corpo para fora da cadeia significante, ou seja,

Lacan, ou "o primeiro Lacan", acreditou, num certo sentido, poder dispensar a referência ao corpo. Isto quer dizer, mais precisamente, que ele pensou poder deixar o corpo fora do simbólico, exterior à articulação significante, e é o sentido profundo que se revela, aqui, de sua distinção clássica do imaginário e do simbólico.

Ele começou situando o corpo na ordem imaginária, como corpo especular, o do estádio do espelho: a libido circulando entre a e a' como libido do eu. No inconsciente, ele não fazia intervir o corporal, senão como simbolizado. Essa construção se tornou tão clássica, tão operatória, (...) que estamos todos marcados por ela, e é um esforço chegar a se desligar desses pressupostos. (p. 94)

Nesse primeiro momento, para Miller (1998, p. 94), Lacan "deixa o corpo e a libido com o imaginário". Mas com o decorrer de sua teoria, "sua construção não pode se sustentar sem que haja, no simbólico, uma satisfação que vise o sujeito".

Assim, o corpo é progressivamente introduzido no ensino lacaniano. Da mesma forma como a necessidade de uma referência ao corpo exige de Freud a introdução do conceito de pulsão, para Lacan, segundo Miller (1998, p. 95), "o corpo é introduzido, mas "na condição de ser simbolizado, de ser significantizado e (...) simbolizado quer dizer mortificado"”.

Com a introdução do registro do Real, conforme assinalado, a teoria lacaniana passa por reformulações e afirma-se nela a referência ao corpo. Ao final de seu ensino, Lacan marca os limites da linguagem, apontando a im- 
portância do corpo, como real que se impõe na clínica e como objeto a. Miller (1998) esclarece, finalmente, que

o corpo entra no ensino de Lacan enquanto objeto $a$. É preciso que se diga que ficamos aí, nesse plano. Ficamos na idéia de que o corpo, mortificado pelo significante, deixa lugar para exceções, restos suplementares que escapam à mortificação e que são os objetos $a$ (...). (p. 97)

Vale notar que as críticas acima citadas podem ser entendidas como dirigidas, não apenas ao pensamento de Lacan, mas à leitura que o próprio lacanismo fez desse autor.

Na clínica, o equívoco consiste em colocar o significante em primeiro plano, apagando o corpo e a pulsão, como se fosse possível operar sobre um campo desintensificado, de pura representação. Nesse posicionamento equivocado, o estereótipo é o do analista mudo e mortificado.

Em oposição, mesmo afirmando o símbolo e a linguagem como estrutura e limite do campo psicanalítico, ao estabelecer o poder das palavras na Psicanálise e na direção da cura, Lacan não defende que se restrinja o campo psicanalítico ao discurso.

Lacan (1955-1956/1988, p. 188) não se mostra surpreso por verificar que seu discurso suscite "uma certa margem de malentendido". Para ele, "o próprio fundamento do discurso inter-humano é o mal-entendido". Este não é "irremediável", pois, ao oferecer a "oportunidade" de não ser completamente compreendido, deixa "sempre a porta aberta para uma retificação progressiva".

Entretanto, Lacan (1955-1956/1988) afirma que dizer que o inconsciente é estruturado como uma linguagem, não significa reduzi-lo ao discurso:

Não digo que o que é comunicado na relação analític a passe pelo discurso do sujeito. Não tenho absolutamente, portanto, de distinguir, no próprio fenômeno da comunicação analítica, o domínio da comunicação verbal do da comunicação préverbal. Que essa comunicação pré ou mesmo extraverbal seja permanente na análise, isso não resta dúvida, mas se trata de ver o que constitui o campo propriamente psicanalítico. (p. 189) 


\section{Michele Cukiert}

Ou seja:

O que constitui o campo analítico é idêntico ao que constitui o fenômeno analítico, ou seja, o sintoma. E também um número enorme de outros fenômenos ditos normais ou subnormais, que não haviam sido até a análise elucidados quanto a seu sentido, estendendo-se para muito além do discurso e da fala, já que se trata das coisas que acontecem ao sujeito na sua vida cotidiana. Depois os lapsos, distúrbios de memória, sonhos, mais o fenômeno do chiste (...). (p. 189)

Mais exatamente, nas palavras de Lacan (1955-1956/1988):

Se digo que tudo o que pertence à comunicação analítica tem estrutura de linguagem, isso não quer dizer que o inconsciente se exprima no discurso. A Traumdeutung, a Psicopatologia da vida quotidiana e o Chiste tornam isso transparente nada dos rodeios de Freud é explicável, salvo que o fenômeno analítico como tal, seja ele qual for, é, não uma linguagem no sentido em que isso significaria ser um discurso - eu nunca disse que é um discurso, mas estruturado como uma linguagem. É nesse sentido que se pode dizer que é uma variedade fenomenal, e a mais reveladora, das relações do homem com o domínio da linguagem. Todo fenômeno analítico, todo fenômeno que participa do campo analítico, da descoberta analítica, daquilo com que lidamos no sintoma e na neurose, é estruturado como linguagem. (p. 192)

Na clínica lacaniana, o analista não toca o corpo (biológico). Paradoxalmente, toca por meio de palavras, sobre o inconsciente e sobre a história, obtendo efeitos. Incide mediante a palavra sobre o campo do inconsciente, estruturado como linguagem. A regra de abstinência, por sua vez, como correlato da livre-associação, corresponde, desde Freud, a uma ética analítica: a da escuta. Isso não significa que Lacan tenha feito uma apologia obsessiva à neutralidade e à mortificação do analista. Essa não parece ter sido sua forma de expressão que, como se pode ler nos depoimentos de J. Miller (1993) e de outros que conviveram intimamente com ele, fez fama com sua ironia, sobressaltos, ataques de cólera, inquietude, impaciência e, é claro, sua coragem e persistência no enfrentamento do duro labor analítico.

Dizer que o inconsciente se estrutura como linguagem não significa dizer, em termos lacanianos, que ele é apenas simbólico. Avançando sobre as idéias freudianas, Lacan articula ao longo de sua obra uma íntima relação entre a linguagem e o organismo, inter-relação que traz consequiências e se 
exprime na construção de nossa subjetividade, nas manifestações da sexualidade, na nossa relação com o outro e na maneira como se conduz a investigação e a terapêutica em Psicanálise.

Cukiert, M. (2004). Some considerations about body and language in Lacan's Theory and clinic. Psicologia USP, 15(1/2), 225-241.

Abstract: The article discusses the relationship between body and language in Lacan's theory and clinic. It discusses critic opinions that with Lacan's emphasis on the language, he has separated the subject in Psychoanalysis from his corporal reality. Finally shows that Lacan's proposal of the unconscious structured as a language doesn't mean that he reduces the analytic phenomenon to the symbolic.

Index terms: Psychoanalysis. Lacanian theory. Body. Lacan, Jacques, 1901-1981.

Cukiert, M. (2004). Quelques considerations sur le corps et le langage dans la théorie et la clinique chez Lacan. Psicologia USP, 15(1/2), 225-241.

Résumé: L'article traite sur les relations entre le corps et le langage (et sa transformation) chez Lacan. Il discute les critiques faites aux formulations lacaniennes selon lesquelles, avec l'emphase sur le langage, Lacan aurait amputé du sujet en psychanalise sa réalité sensible. Il mo ntre que Lacan postule l'inconscient structuré en tant que langage et n'exclut pas le caractère corporel de son schéma mental et ne réduit pas le phénomène analytique au symbolique (discours).

Mots-clés: Psychanalise. Theorie lacanienne. Corps. Lacan, Jacques, $1901-1981$ 


\section{Michele Cukiert}

\section{Referências}

Birman, J. (1998). A mais-valia vai acabar, seu Joaquim: Sobre o malestar da psicanálise. In C. A. Kishida et al., Cultura da ilusão. Textos apresentados no IV Fórum Brasileiro de Psicanálise, setembro de 1997, Rio de Janeiro. Contra Capa.

Cesarotto, O., \& Leite, M. P. de S. (1993). Jaques Lacan: Uma biografia intelectual. São Paulo: Iluminuras.

Chemama, R. (1995). Dicionário de psicanálise. Porto Alegre: Artes Médicas.

Cukiert, M. (2000). Uma contribuição à questão do corpo em psicanálise: Freud, Reich e Lacan. Dissertação de Mestrado, Instituto de Psicologia, Universidade de São Paulo, São Paulo.

Fink, B. (1998). O sujeito lacaniano: Entre a linguagem e o gozo. Rio de Janeiro: Jorge Zahar.

Katz, C. S. (1992). Introdução. In S. Leclaire, O corpo erógeno. São Paulo: Escuta.

Lacan, J (1982). O seminário. Livro 20: Mais ainda. Rio de Janeiro: Jorge Zahar. (Trabalho original publicado em 1975)

Lacan, J. (1985). O seminário. Livro 2: O Eu na teoria de Freud e na técnica da psicanálise. Rio de Janeiro: Jorge Zahar. (Trabalho original publicado em 1954 1955)

Lacan, J. (1988). O seminário. Livro 3: As psicoses. Rio de Janeiro: Jorge Zahar. (Trabalho original publicado em 1955-1956)

Lacan, J. (1988). O seminário. Livro 11: Os quatro conceitos fundamentais da psicanálise. Rio de Janeiro: Jorge Zahar. (Trabalho original publicado em 1964)

Lacan, J. (1992). O seminário. Livro 17: O avesso da psicanálise. Rio de Janeiro: Jorge Zahar. (Trabalho original publicado em 1969-1970)

Lacan, J. (1998). Função e campo da fala e da linguagem em psicanálise. In J. Lacan, Escritos (pp. 238-324). Rio de Janeiro: Jorge Zahar. (Trabalho original publicado em 1953)

Lacan, J. (1998). Posição do inconsciente no Congresso de Bonneval. In J. Lacan, Escritos (pp. 843-865). Rio de Janeiro: Jorge Zahar. (Trabalho original publicado em 1960)

Laplanche, J., \& Pontalis, J.-B (1983). Vocabulário da psicanálise. São Paulo: Martins Fontes.

Miller, J. (1993). Apresentação. In F. Giroud, Lacan, você conhece? São Paulo: Cultura. 
Considerações Sobre Corpo e Linguagem na Clínica e na Teoria Lacaniana

Miller, J-A. (1998). O osso de uma análise. Revista da Escola Brasileira de PsicanáliseBahia (Número especial de agente). Seminário proferido no VIII Encontro Brasileiro do Campo Freudiano, Salvador.

Nasio, J. -D. (1993). Cinco lições sobre a teoria de Jacques Lacan. Rio de Janeiro: Jorge Zahar.

Robertie, L. de la. (1992). O corpo: Textos de Jacques Lacan. In D. Maurano (Org.), Circulação psicanalítica (pp. 255-272). Rio de Janeiro: Imago.

Roudinesco, E., \& Plon, M. (1998). Dicionário de psicanálise. Rio de Janeiro: Jorge Zahar.

Recebido em 09.06.2004 Aceito em 06.08.2004 